\title{
The Leadership of Knowledge in Organization: The Media Needs of the Audience with Emphasis on Habermas Public Sphere Theory in Media Organizations
}

\author{
Ali Asadnezhad ${ }^{1}$, Nahid Kordi ${ }^{*}$, Ali Jafari ${ }^{3}$ \\ ${ }^{1}$ Department of Communication Sciences, Ardabil Branch, Islamic Azad University, Ardabil, Iran \\ $2^{2 *}$ Department of Communication Sciences, East Tehran Branch, Islamic Azad University, Tehran, Iran \\ ${ }^{3}$ Department of Communication Sciences, Ardabil Branch, Islamic Azad University, Ardabil, Iran
}

\section{Keywords: \\ Leadership of Knowledge, Knowledge Sharing, Media Needs, Public Sphere, Social Media}

\section{Received}

25 Janauary 2021

Received in revised form

15 February 2021

Accepted

24 February 2021

*Correspondence:

nahid.kordi@gmail.com

\begin{abstract}
This study examines Habermas's public Sphere theory in relation to the leadership of knowledge in organizations based on the audience's media needs and prioritizes them. In this study, after conducting library studies and compiling a comprehensive and complete theoretical literature and research background, a questionnaire was designed and distributed among the respondents in line with related research theories and research questions and hypotheses. The data collection method is a survey type. The statistical population of the research consists of cyberspace users. The sample size was determined based on Cochran's formula, and 384 participants were selected using a purposive non-random sampling method. The results showed that the most important effects were Internet access, logical and rational critique of political, economic, social, and cultural issues, two-way and free discussion with government officials on social networks. The results also showed that knowledge leadership has an essential role in promoting organizational knowledge, organizational culture, and knowledge management. The knowledge management in the organization is done through social networks.
\end{abstract}

In the information age, the main advantage lies in the knowledge capital. The increasing role of knowledge, innovation, and new technologies in creating strategic benefits and the importance of knowledge resources in the management of organizations has led to knowledge management at the heart of organizations' strategic policies. The present century is the century of exploiting knowledge to aid development. One of the essential factors in the success of knowledge management is 
knowledge sharing. Efficient knowledge sharing enables people to produce and create the knowledge they need in the best way (Alipour, 2015). In recent years, various organizations and companies have begun to join the knowledge process. On the other hand, Social networks are among the most important tools for knowledge sharing in organizations.

Since the beginning of the twentieth century, the growth and expansion of mass media and media have overshadowed human life. Citizens need to understand this new space both for the media community and media sources. The formation of these new spaces was also influential in political thought as dialogue in the public sphere in Jurgen Habermas' theory reflected more than any of his theories (Hollab, 1997). The public sphere is a space for comment, discussion, debate, and resolution on public issues, and everyone has the potential right and power to participate in it.

Habermas uses the term (public sphere) to refer to the social sphere. Individuals share a set of values, positions, orientations, and values through equal communication in a situation without pressure, urgency, or coercion, based on freedom and interactive awareness and an equal footing for all parties involved. They produce in the public sphere, which ultimately acts as an effective tool to influence the state's behavior and performance, especially in state power rationalization (Nozari, 2002). Therefore, the present situation provides the context in which the verbal action ultimately manifests itself in its most desirable form \" communicative action $\backslash "$ or \"conceptual actionl" sphere (O'Brien, 2003). There are three elements of the public sphere from Habermas's point of view (Habermas, 2006): 1) The public sphere needs a place of exchange that is accessible to all and where social experiences and perspectives can be expressed and exchanged, 2) in the public sphere rational and logical discussions of perspectives and points of view take place, and 3) systematic and critical oversight and oversight of government policies is the primary task of the public sphere (O’Brien,2003).

According to Habermas (1989), the public sphere was the birthplace of the main features of the expanding capitalist society in England in the 18th century. The decisive factor was that the capitalist entrepreneurs were rich enough to fight for independence from the state and the church. Moreover, they got what they wanted. Previously public life was dominated by clergy and court with their usual focus on the formidable display of feudal relations. However, as the wealth of those seeking capital increased, this superiority was undermined. The result was that the capitalists gave more support to the world of "words", theatre, art, coffee house, shop, fiction; the order reduced their dependence on their supporters and led to forming a sphere independent of traditional powers. Habermas stated that, in this regard, dialogue became criticism; criticism and meaningful words became argument (Mehdizadeh, 2004). Habermas traces the historical and spatial origins of the emergence of the public sphere within open halls and public forums. Pioneers of literary and political enlightenment are clubs, cafes, newspapers, and the press. Numerous debates and discussions occur in these forums and center on the role of tradition (Nozari, 2002).

At the same time, in Iran, before the advent of new media, places such as mosques, cafes, traditional markets, cafes were known as public spaces where people discussed various political, economic, and cultural issues. Due to the fact that the media space in Iran faced many restrictions for the expansion of the Internet and mobile phones, the possibilities of media convergence had made cyberspace popular with Iranian audiences. Still, new media acted as options for traditional public space and time constraints. Social, political, and cultural conditions and the limitations of Iran's traditional public sphere paved the way for users to enter new platforms centered on communication technologies. Therefore, the expansion of new media and its various forms, 
including social networks, can indicate a change in Iran's traditional public sphere (Seyed Alavi \& Naqib al-Sadat, 2011). In Iran, despite the filtering of social networks (Facebook, Telegram), many young people have become members of these networks due to the diversity of these networks' space in communication, free exchange of information, and the lack of a public arena. This issue has arisen due to the attention paid to the new media space, which is affected by the decentralization of the media and the pervasiveness of citizens' access to it.

\section{Background Research}

Yazd khasti et al. (2014) found that promoting communication and information exchange in virtual social networks promoted dialogue; it is also restricted and confusing. The limitation is that the uneven distribution of opportunities arises from the possibilities associated with such technologies, and the special status of the virtual public sphere also disrupts intercultural dialogue. Virtual social networks limit and interfere with the intercultural dialogue through the virtual public sphere they create.

Seyed Alavi and Naqib al-sadat (2011) found that the public sphere has been formed by the perspective of communication science and political science experts in the country's universities. The findings showed that public sphere theory could be applied in the virtual sphere. However, cyberspace and computer-mediated communication characteristics have made the public sphere a multifaceted and fragmented space that differs from the traditional public sphere model.

Rabiei and Ismaili (2010) compared Habermas's public sphere model with social-political blogs in Iran. Thus, five active blogs in cyberspace were purposely selected and analyzed using qualitative content analysis. The findings show that although blogs' space leads to increased access to information, it is more of a minor issue and has a little qualitative impact. We see a fragmentation of information in blogs because everyone in the blogosphere writes and speaks, but no one is a reader or listener, and most blog content remains. Another result of this research is that if we consider the critical attitude as one of the public sphere components, blogs have been able to play a valuable role in shaping the public domain in this regard. The high level of filtering in blogs well demonstrates the legitimacy of a critical attitude. Finally, it can be said that blogs have the necessary capabilities and facilities to revive the public sphere, but in action, they have not helped to create the public sphere.

Khaniki and Alvandi (2011) addressed citizenship media and their role in forming an alternative public sphere and dialogue. In this study, there are theoretical discussions about developing an alternative public domain in the theoretical dimension and its dependence on comprehensive and diverse media such as the Internet and then the evolution and formation of citizen media and their place in the new media ecosystem. In this study, five active citizen journalism sites have been selected that serve as examples of citizen media in creating dialogue and shaping the public sphere. Finally, the activities and management of these media were examined, and it was shown what characteristics the selected samples have and what challenges they faced.

Najafi and Niblom (2006) examined how Iranian users use the Internet, blogging, freedom of expression, government, censorship restrictions, and virtual communities and conclude that the Internet has influenced and created public and private domains. The virtual domain has created a space where people can express themselves by escaping the public and private spheres' limitations. When someone writes a political blog using the Internet, they work in cyberspace, despite the limitations of the public domain. Blogs can initiate political debates accessible to many people and affect the public sphere (Naqib al-Sadat, 2012). 
Tong (2015) studied the role and importance of emotions in public life and how people disseminate their feelings through the Internet and new media, and the formation of a controversial public sphere emphasized in new media. This study pays attention to the media needs with the advent of the Internet and the construction of a particular type of public sphere in this space and deals with how the audience is confronted and their feelings in this field.

Rasmassen (2013), in his study about Internet-based media and the public political sphere, emphasizes the level of democratized access to the media, which led to a revision of Habermas's public sphere theoretical space to form a public sphere in the Internet space.

However, Kelly and Etling (2008) conducted the most extensive research on the Iranian blogging space. Their research shows that Iranian blogging is a broad discourse network with particular content regarding the topics discussed and the various spectrums of bloggers.

\section{Theoretical Foundations}

\section{Free Information Theory}

The founders of this theory are Lasswell, Wilbursham, Lazaresfeld, and Rogers. Concepts such as freedom of information and free flow of information have been outlined in the 1948 Universal Declaration of Human Rights (Motamed Nejad, 2004). Freedom of information or the free flow of information is the natural outcome of the primary right to freedom of expression and opinion. In today's societies, information and access to it are tools of power and information flow requires the following factors (Motamed Nejad, 2004): 1) 'Information source' or message or sender generator, 2) The message or information to be sent, 3) A carrier or communication channel through which the message is transmitted and transmitted, and 4) The recipient or recipient who converts the message into knowledge (Motamed Nejad, 2004). Freedom of information is based on the following four basic principles (Motamed Nejad, 2004):

A: Free access to events. Freedom of information will be ineffective if journalists have limited access to the scene and the news source or if journalists are denied the right to collect news at the scene. In either case, freedom of information is lost, and news owners' information about events is often unreliable. So, it should not be forgotten that the principle of free access to the venue and source of news, both inside and outside, often faces many difficulties and is not easily accomplished.

B: Free flow of information. The free flow of information is an essential condition of information. For this reason, if reporters cannot access their news reports through the means of telecommunications (telegraph, telex, telephone, fax, and computer), free access to events is also in vain. Because in this case, hiding the news and not publishing it damages the news and makes the information obsolete.

C: Freedom of Information Release. An important element of freedom of information is the free dissemination of events and the dissemination of ideas. Among the various aspects of freedom of information, this is the only aspect guaranteed in Article 11 of the Declaration of Human Rights and Citizenship of the French Revolution and its constitutions common laws and judicial procedures of the liberal countries. This aspect makes it possible to disseminate information provided it is transmitted to newspapers and other mass media. Therefore, the free dissemination of information is the basis for freedom of information.

D: Freedom of Information. The three elements (i.e., Free access to events, Free flow of information, and Freedom of Information) would be ineffective if the target audience deprive of their freedom of choice and unable to access newspapers magazines and radio and television 
programs news films and online database content. For this reason, the theory of libertarianism is concerned not only with the question of the supply of information but also with the demand for it. Therefore, libertarian theory in this area focuses not only on the issue of information supply but also on demand. According to libertarian theory, citizens should be free to receive the information they want through the press, radio and television programs, news films, and various electronic databases due to some legal restrictions. However, it should be borne that there is a great gap between the principle of freedom of information and the existing facts such as the search and transfer, and release of information. It is usually difficult and generally impossible to obtain information freely for everyone (Webster, 2002).

According to Habermas, in modern media, the main task of the public sphere is to identify social issues and problems that need public attention. In today's world, the public sphere must act as the watchdog of government and interact with the various institutions of government. Today's public areas are far from old-fashioned face-to-face communications characterized by small diversity and dispersed networks that utilize modern means of producing and distributing information to influence the social and political scene. In describing the media's role and function in the public sphere, Habeas writes that this type of communication requires specific means of dissemination and expansion when the public is large. Today, newspapers, publications, radio, and television are the public sphere media (Nozari, 2002).

Habermas's public sphere is the intermediary between the formal government (the public authority) that controls the means of violence and the private sphere (civil society). Moreover, it is characterized by government oversight and transparency of political and administrative decisions, one of the first public sphere goals. Moreover, to secure this position, rational-legal principles are institutionalized, and the observance of those principles becomes binding on everyone. Habermas believed that constituencies are formed in any environment where public issues are debated and debated. The growth and expansion of the public sphere are not necessarily a function of modernization and modernism. The growth and expansion of the public sphere are not necessarily a function of modernization and modernism, and even the public sphere can be formed in a traditional society. The expansion of the public sphere is, in fact, a function of the emergence of free speech and reason and respect. In a favorable atmosphere in the public sphere, private individuals who have come together and expanded their public activities by forming a community seek to pursue public interests more thoughtfully and efficiently. In that case, the central and essential thing they need is expanding communication and communication among them. The influence of communication and communication between them will increase effectively. However, the expansion of this relationship requires the existence of special tools and facilities. In general, it can be said that the free flow of information and the public sphere is entirely in line and have the same conditions. If the free flow of information is censored or restricted, the general public will be restricted in obtaining news and information and access to each other.

\section{Habermas Public Sphere Theory}

Habermas uses the term public sphere to mean social spheres in which individuals, through dialogue, communication, and reasoning, adopt value orientations that have an informative and rationalizing effect on the process of exercising state power (Nozari, 2002). In other words, individuals in the public sphere through dialogue and reasoning and in a situation free from any pressure, internal or external coercion and based on freedom and interactive awareness and in equal conditions for participants, a set of behaviors, situations, and orientations has produced value. It is 
ultimately an effective tool for influencing government behavior and performance, especially in rationalizing state power (Nozari, 2002).

In explaining the concept of his public sphere Habermas (2006) writes that "by the public sphere, we mean the realm of our social life in which something like public opinion can take shape. In principle, all citizens should have access to the public sphere. In the course of any conversation, during which private individuals come together to form a community, a part of the public sphere is formed. Citizens or individuals who have come together not as economic or professional individuals, only care about their private affairs and are obliged to obey and abide by these rules. Instead, citizens and private individuals act as the public when they can address public interest issues or public interest without coercion" (p. 34). In his classic narrative of the emergence of the bourgeois public sphere, Habermas explains the historical convergence of democratic principles, the new adventures of communication and propaganda with enlightened belief. The public sphere is an open forum for all citizens in which public and political issues of interest are discussed and exchanged. This field remains distinct from the state, and since this field is the place of rational criticism, it acts as a restraint on state power (Rabiei et al., 2012).

Thus, the civic sphere, which is part of the public sphere, has a political orientation rooted in civil society's communication processes and is the most important mediator between citizens and their elected officials in a constitutional democracy and exerts influence over the government through the Legislative Assembly (Cohen, 2004). Accordingly, this public sphere is a political space in which individuals' rights are recognized as free and equal citizens, and the political community is formed. Since communication in the ideal state of dialogue is free from any compulsion, dialogue in the public sphere can lead to democratic development at all levels of society (Habermas, 2006). Table 1 shows the independent and dependent variables according to Habermas public sphere theory.

Table 1

Audience Priorities and Media Needs

\begin{tabular}{|c|c|c|}
\hline Priorities & $\begin{array}{l}\text { Independent variable: } \\
\text { Media priorities and needs of the audience }\end{array}$ & $\begin{array}{l}\text { The dependent variable: } \\
\text { Formation of Habermas' public sphere in social networks }\end{array}$ \\
\hline 1 & Free Internet access & Areas in which individuals come together to participate in discussions. \\
\hline 2 & Free access to social networks & The principle of equality and access to the public sphere for all \\
\hline 3 & $\begin{array}{l}\text { Critique public power (government) on } \\
\text { social networks without any fear, pressure or } \\
\text { threat }\end{array}$ & $\begin{array}{l}\text { The public sphere is the primary form of the public political sphere, namely the } \\
\text { field of state policy making that deals with cultural affairs. }\end{array}$ \\
\hline 4 & $\begin{array}{l}\text { Free, rational and rational commentary on } \\
\text { criticizing the political, economic, social and } \\
\text { cultural conditions of society }\end{array}$ & $\begin{array}{l}\text { Communication or verbal action (Habermas's point of departure to the public } \\
\text { sphere), where the correctness of speech in speech and in criticizing the issues } \\
\text { of reasoning is superior and stronger. }\end{array}$ \\
\hline 5 & $\begin{array}{l}\text { Freely Interviewed (Citizens) with } \\
\text { Government Officials and Criticizes Their } \\
\text { Performance }\end{array}$ & $\begin{array}{l}\text { The public arena is rooted in the private arena and is formed by citizens' } \\
\text { discussion of public affairs. } \\
\text { Is the private sphere attracted by the government and permitted to speak in } \\
\text { accordance with its interests and affiliation with the government? Or he is } \\
\text { separate from the government and criticizes the government with political } \\
\text { impunity. }\end{array}$ \\
\hline 6 & $\begin{array}{l}\text { Two-way dialogue (audience) with } \\
\text { government officials and freely criticizing } \\
\text { their performance }\end{array}$ & $\begin{array}{l}\text { Two-way and free conversation of the audience (everyone) with government } \\
\text { officials on social networks }\end{array}$ \\
\hline
\end{tabular}




\section{Method}

The research method is a survey. In this research, after conducting library studies and a complete and comprehensive compilation of theoretical literature and research background, a questionnaire was designed and compiled according to research-related theories and research questions and hypotheses and distributed among the respondents. The statistical population consists of cyberspace users, whose number is estimated to be more than several million people. Moreover, according to the Morgan table, the statistical sample of more than 10 thousand people shows that the statistical sample is equal to 384 people. Therefore, 384 people have been determined as a statistical sample following this formula and have completed a questionnaire.

\section{Validity and Reliability of the Data}

There are several ways to determine the validity of a measuring instrument. In this study, the researcher used content validity to assess the validity of items of questionnaires. Content validity means the extent to which a practical tool covers the content domain. Therefore, to check the content validity of this research, the questionnaires were provided to experts related to the research topic, including the supervisor, experts of higher levels, to provide their comments and suggestions on the content of the questionnaire items appropriate to its research purpose. After receiving the questionnaire, the proposed corrections were applied to have the necessary content validity. In this study, as in many other studies, Cronbach's alpha was used to measure the measurement tool's reliability. Cronbach's alpha coefficient is a number between zero and one. An alpha coefficient of less than .6 indicates poor reliability. Alpha above .7 to .8 indicates relatively good reliability, and alpha above .8 indicates a high reliability of the measuring instrument. Table 2 shows the reliability of research variables.

Table 2

\begin{tabular}{lc} 
Reliability of Research Variables & $\begin{array}{c}\text { Number of items } \\
\text { Cronbach's alpha } \\
\text { coefficients }\end{array}$ \\
\hline $\begin{array}{l}\text { Free access of the audience to the Internet } \\
\text { Access to social networks }\end{array}$ & 14 \\
Use of social networks (Telegram and Instagram) & 89 \\
Criticism of public power (government) on social networks (Telegram and Instagram) & 13 \\
Rational and rational critique of political, economic, and cultural issues on social networks & .83 \\
(Telegram and Instagram) & .87 \\
$\begin{array}{l}\text { Two-way conversation between the audience and government officials on social networks } \\
\text { (Telegram and Instagram) }\end{array}$ & 13 \\
Formation of the public sphere & .89 \\
\hline
\end{tabular}

\section{Results}

\section{Descriptive Demographic}

As shown in Table 3, 242 respondents were male (.63), and 142 (.37) were female. Of the total number of respondents, 70 (17.9) were between 20 and 30 years of age, 131 (33.6) were between 30 and 40 years, 118 (30.3) were between 40 and 50 years, and 70 (17.9) were over 50 years of age, and .3 did not answer this question. Of the total number of respondents, 8 (2.1) had a diploma degree, 21 (5.5) had an Associate Degree, 157 (40.9) had a Bachelor's degree, 133 (34.6) had an M.A, and 64 (16.7) had a Ph.D. degree. One person (.3) did not answer the question. 
Table 3

Frequency Distribution by Gender of Respondents

\begin{tabular}{llcc}
\hline & & Number & Percent \\
\hline Gender & Man & 242 & 0.63 \\
& Woman & 142 & 0.37 \\
Age & Collecting & 384 & 100 \\
& $20-30$ & 70 & 18.2 \\
& $30-40$ & 129 & 33.6 \\
& $40-50$ & 117 & 30.5 \\
& 50 and above & 67 & 17.4 \\
Education & Unanswered & 1 & 0.3 \\
& Collecting & 384 & 100 \\
& Diploma & 8 & 2.1 \\
& Associate Degree & 21 & 5.5 \\
& Bachelor & 157 & 40.9 \\
& M.A & 133 & 34.6 \\
& P.HD & 64 & 16.7 \\
& Unanswered & 1 & 0.3 \\
& Total & 384 & 100 \\
\hline
\end{tabular}

\section{Prioritize Audience Media Needs}

\section{Free Internet Access}

Table 4 shows that 384 respondents completed a questionnaire. Of these, 157 (40.8) respondents had free access to the Internet as their first priority, 49 (13.1) respondents as their second priority, 77 (20.3) respondents as their third priority, 53 (13.6) respondents as their fourth priority, 34 (8.7) respondents as their fifth priority, and 14 (3.6) respondents as their sixth priority.

Table 4

Free Internet Access

\begin{tabular}{|c|c|c|c|c|c|c|c|c|c|c|c|c|}
\hline Title & \multicolumn{12}{|c|}{ Priorities } \\
\hline \multirow{3}{*}{$\begin{array}{c}\text { Free internet } \\
\text { access }\end{array}$} & \multicolumn{2}{|c|}{ priority 1} & \multicolumn{2}{|c|}{ priority 2} & \multicolumn{2}{|c|}{ priority 3} & \multicolumn{2}{|c|}{ priority 4} & \multicolumn{2}{|c|}{ priority 5} & \multicolumn{2}{|c|}{ priority 6} \\
\hline & number & $\%$ & number & $\%$ & number & $\%$ & number & $\%$ & number & $\%$ & number & $\%$ \\
\hline & 157 & 40.8 & 49 & 13.1 & 77 & 20.3 & 53 & 13.6 & 34 & 8.7 & 14 & 3.6 \\
\hline
\end{tabular}

\section{Free Access to Social Networks}

Table 5 shows that 127 (32.8) respondents had free access to social networks as their first priority, 70 (18.2) respondents as their second priority, 88 (22.8) respondents as their third priority, 53 (13.8) respondents as their fourth priority, 33 (8.7) respondents as their fifth priority, and 13 (3.6) respondents as their sixth priority.

Table 5

Free Access to Social Networks

\begin{tabular}{|c|c|c|c|c|c|c|c|c|c|c|c|c|}
\hline Title & \multicolumn{12}{|c|}{ Priorities } \\
\hline \multirow{3}{*}{$\begin{array}{c}\text { Free access to } \\
\text { social } \\
\text { networks }\end{array}$} & \multicolumn{2}{|c|}{ priority 1} & \multicolumn{2}{|c|}{ priority 2} & \multicolumn{2}{|c|}{ priority 3} & \multicolumn{2}{|c|}{ priority 4} & \multicolumn{2}{|c|}{ priority 5} & \multicolumn{2}{|c|}{ priority 6} \\
\hline & number & $\%$ & number & $\%$ & number & $\%$ & number & $\%$ & number & $\%$ & number & $\%$ \\
\hline & 127 & 32.8 & 70 & 18.2 & 88 & 22.8 & 53 & 13.8 & 33 & 8.7 & 13 & 3.6 \\
\hline
\end{tabular}

\section{Free Access to Social Media}

As presented in Table 6, among the respondents, 127 (32.3) freely used social media as their first priority, 59 (15.4) as their second priority, 93 (24.1) as their third priority, 55 (14.4) respondents as their fourth priority, 40 (10.5) as their fifth priority, and 12 (3.3) respondents as their sixth priority. 
Table 6

Free Access to Social Media

\begin{tabular}{|c|c|c|c|c|c|c|c|c|c|c|c|c|}
\hline Title & \multicolumn{12}{|c|}{ Priorities } \\
\hline \multirow{3}{*}{$\begin{array}{c}\text { Free access } \\
\text { to social } \\
\text { media }\end{array}$} & \multicolumn{2}{|c|}{ priority 1} & \multicolumn{2}{|c|}{ priority 2} & \multicolumn{2}{|c|}{ priority 3} & \multicolumn{2}{|c|}{ priority 4} & \multicolumn{2}{|c|}{ priority 5} & \multicolumn{2}{|c|}{ priority 6} \\
\hline & number & $\%$ & number & $\%$ & number & $\%$ & number & $\%$ & number & $\%$ & number & $\%$ \\
\hline & 127 & 32.3 & 59 & 15.4 & 93 & 24.1 & 55 & 14.4 & 40 & 10.5 & 12 & 3.3 \\
\hline
\end{tabular}

\section{Freely Criticizing Government Performance (Public Power) on Social Media}

As presented in Table 7, among the respondents, 93 (24.8) respondents freely criticized the performance of government (public power) in social networks as their first priority, 57 (14.9) respondents as their second priority, 117 (30.3\%) respondents as their third priority, 64 (16.7) respondents their fourth priority, 37 (9.7) respondents their fifth priority, and 16 (4.4) respondents as their sixth priority.

Table 7

Freely Criticizing Government Performance (Public Power) on Social Media

\begin{tabular}{|c|c|c|c|c|c|c|c|c|c|c|c|c|}
\hline Title & \multicolumn{12}{|c|}{ Priorities } \\
\hline \multirow{3}{*}{$\begin{array}{c}\text { Public Power } \\
\text { on social } \\
\text { media }\end{array}$} & \multicolumn{2}{|c|}{ priority 1} & \multicolumn{2}{|c|}{ priority 2} & \multicolumn{2}{|c|}{ priority 3} & \multicolumn{2}{|c|}{ priority 4} & \multicolumn{2}{|c|}{ priority 5} & \multicolumn{2}{|c|}{ priority 6} \\
\hline & number & $\%$ & number & $\%$ & number & $\%$ & number & $\%$ & number & $\%$ & number & $\%$ \\
\hline & 93 & 24.8 & 57 & 14.9 & 117 & 30.3 & 64 & 16.7 & 37 & 9.7 & 16 & 4.4 \\
\hline
\end{tabular}

\section{Rational Commentary on Political, Economic, Social, and Cultural Issues in Social Networks} As shown in Table 8, among the respondents, 85 (22.3) respondents chose the topic of rational comment on political, economic, social, and cultural issues on social networks as their first priority, and 72 (18.7) respondents as their second priority, 106 (27.7) respondents as their third priority, 54 (14.1) respondents as their fourth priority, 48 (13.3) respondents as their fifth priority, and 19 (4.9) respondents as their sixth priority.

Table 8

Rational Commentary on Political, Economic, Social, and Cultural Issues in Social Networks

\begin{tabular}{|c|c|c|c|c|c|c|c|c|c|c|c|c|}
\hline Title & \multicolumn{12}{|c|}{ Priorities } \\
\hline \multirow{3}{*}{$\begin{array}{c}\text { Free use of } \\
\text { social } \\
\text { networks }\end{array}$} & \multicolumn{2}{|c|}{ priority 1} & \multicolumn{2}{|c|}{ priority 2} & \multicolumn{2}{|c|}{ priority 3} & \multicolumn{2}{|c|}{ priority 4} & \multicolumn{2}{|c|}{ priority 5} & \multicolumn{2}{|c|}{ priority 6} \\
\hline & number & $\%$ & number & $\%$ & number & $\%$ & number & $\%$ & number & $\%$ & number & $\%$ \\
\hline & 85 & 22.3 & 72 & 18.7 & 106 & 27.7 & 54 & 14.1 & 48 & 13.3 & 19 & 4.9 \\
\hline
\end{tabular}

\section{Two-way Dialogue (Audience) with Government Officials and Freely Criticizing their Performance}

Table 9 shows that the two-way dialogue (audience) with government officials and freely criticizing their performance were the first priority of $82(.21)$ respondents, the second priority of 53 (13.8) respondents, the third priority of 91 (23.8) respondents, the fourth priority of 72 (18.7) respondents, the fifth priority of $62(15.9)$ respondents, and the sixth priority of $24(6.4)$ respondents.

Table 9

Two-way Dialogue (Audience) with Government Officials and Freely Criticizing their Performance

\begin{tabular}{|c|c|c|c|c|c|c|c|c|c|c|c|c|}
\hline Title & \multicolumn{12}{|c|}{ Priorities } \\
\hline \multirow{3}{*}{$\begin{array}{c}\text { Free access } \\
\text { to social } \\
\text { media }\end{array}$} & \multicolumn{2}{|c|}{ priority 1} & \multicolumn{2}{|c|}{ priority 2} & \multicolumn{2}{|c|}{ priority 3} & \multicolumn{2}{|c|}{ priority 4} & \multicolumn{2}{|c|}{ priority 5} & \multicolumn{2}{|c|}{ priority 6} \\
\hline & number & $\%$ & number & $\%$ & number & $\%$ & number & $\%$ & number & $\%$ & number & $\%$ \\
\hline & 82 & 21 & 53 & 13.8 & 91 & 23.8 & 72 & 18.7 & 62 & 15.9 & 24 & 6.4 \\
\hline
\end{tabular}




\section{Multivariate Simple Regression Analysis}

Table 10 shows the simultaneous effect of independent variables on dependent variables (formation of the public sphere in Telegram and Instagram social networks), which has the most significant effect in the first order of Internet access $(\beta=.42)$. The second-order is a logical and rational critique of political, economic, social, and cultural issues in social networks (Telegram and Instagram) ( $\beta$ $=.39$ ). The third order is a two-way and free dialogue between the audience and government officials in social networks (Telegram and Instagram) $(\beta=.38)$. The fourth-order is using social networks (Telegram and Instagram) $(\beta=.17)$.

The coefficient of determination shows that the total variance of the dependent variable is .89 . This means that the sum of the independent variables accounted for $89 \%$ of the dependent variable changes i.e., . 11 of the public sphere formation in the telegram and Instagram social networks. The regression equation below shows the relative effects of the independent variables on the dependent variable:

$\mathrm{Y}=\beta 1 \mathrm{Z1}+\beta 2 \mathrm{Z2}+\beta 3 \mathrm{Z3}+\mathrm{ei}$

Free Internet Access +(.42) Free Access to Social Networks +(.39) Use of Social Media (Telegram and Instagram) $+(.38)$ Public Power (Government) Criticism by Social Network Audiences (Telegram and Instagram) + (.17) The rational and rational critique of political, economic, social and cultural issues in Social Networks (Telegram and Instagram) (.17) Two-way and Free Audience Chat (all) with Government Officials in Social Networks (Telegram and Instagram) (.16) = Formation of Public Sphere in Telegram and Instagram.

Table 10

Multivariable Simple Regression Analysis

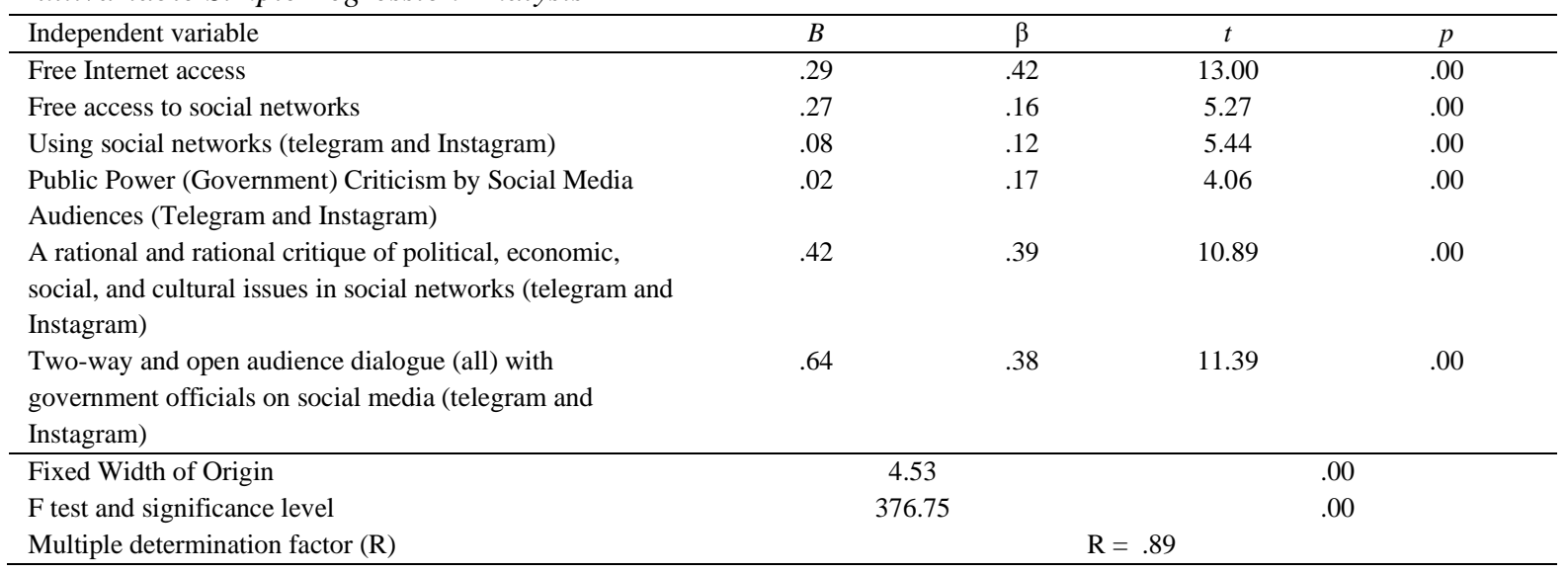

\section{Discussion and Conclusion}

This study investigated the formation of Habermas public domain theory in Instagram and Telegram social networks. Virtual social networks are a type of contact pattern in which a technical base and Internet infrastructure support the interaction and communication between network agents. In these networks, a common goal, interest, or need can be a connecting element that makes related factors feel that they are in a real community, even without physical presence. Based on the basic components of the formation of the Habermas public sphere in the social networks such as Telegram and Instagram, there are free access to social networks, the ability to critique public power (government), a logical and rational critique of political, economic, social and cultural issues, twoway dialogue and free audience which the Government officials would be able to consider in social networks communications and plan to use them as a new media, or a platform for the emergence 
and manifestation of each of public policy. People can speak about and interact with their favorite issues through social media. Through this, public opinion can be formed as the people's voice, and everyone can take action against social and political issues.

The expansion of cyberspace has provided citizens with greater access to various socio-political and cultural information. With features such as lack of control, decentralization, flexibility, easy access to any information, two-way dialogue, it allows you to publish any information that promises an equal world.

This study's findings showed that this space, as a kind of virtual public sphere, despite the unequal distribution of various capitals, provides superficial information, entertaining aspect, citizens' access to a different story, and the possibility of discussing multiple topics. The findings are consistent with Khaniki and Alvandi's (2011) results. In this study, during the theoretical discussions, the formation of an alternative public domain in the theoretical dimension and its dependence on a comprehensive and diverse media such as the Internet was investigated. Then, the evolution and formation of citizen media and their place in the new media ecosystem were examined. Seyed Alavi and Naqib al-Sadat (2011) found that public sphere theory can be used in cyberspace. Still, the characteristics of cyberspace and computer-mediated communications have made the public domain a multiple and fragmented space that is different from the traditional model of the public sphere. The research results of Rabiei et al. (2012) indicate that although people can comment, this factor has not been able to help the formation of dialogue as one of the goals of the public sphere. Of course, if we consider the critical attitude as one of the public sphere components, blogs have been able to play a useful role in shaping the public sphere in this regard.

Findings of the present research show that in terms of structure, Instagram and Telegram social networks provide countless possibilities, including unlimited ability to publish information, provide comments, share files, play videos, ..., that provides equal opportunities for users. By connecting to the Internet, users can take advantage of the facilities that promise a free and equal society and become potential and active members of society.

The majority of users and audiences agree with the formation of the public sphere (critique of public power of government, the logical and rational critique of political, economic, social, and cultural issues, the two-way and free dialogue of audiences with government officials on social networks (Telegram and Instagram)). The studies that have been done so far about Habermas' public domain have been one-dimensional about the positive and negative conditions of activity in this cyberspace. However, in this study, we have addressed the components and media priorities of the audience in criticizing the government's performance, given the depth of Habermas' public sphere that is the innovation of this research.

\section{References}

Alipour, Z. (2015). Presenting a combined model to share Islamic Azad University faculty members' knowledge with the approach of perceptual factors. Journal of Information Technology Management, 6(1), 107-126.

Cohen, J. (2004). Public sphere, media and civil society, (L. Kavousi, Tran.). Journal of the Specialty of Media and Public Sphere, $59(1), 45-69$.

Habermas, J. (1989). The structural transformation of the public sphere. Cambridge: The MITP.

Habermas, J. (2006). Political communication in media society: Does democracy still enjoy an epistemic dimension? The impact of normative theory on empirical research. Communication Theory, 16(4), 411-426.

Hollab, R. (1997). Jurgen Habermas Criticism in the Public Sector (H. Bashirieh, Tran.) Tehran: Publication. 
Kelly, J., \& Etling, B. (2008). Mapping Iran's Online Public: Politics and Culture in the Persian Blogosphere. Retrieved from www.cyber.law.harvard.edu.

Khaniki, H., \& Alvandi, P. (2011). Citizen media and the alternative public sector: A case study of five active citizen journalism sites in Iran. Social Science Quarterly, 17(51), 139-188.

Mehdizadeh, S. M. (2004). Internet and public sphere. Media Quarterly, 59(1), 111-121.

Motamed Nejad, K. (2004). Iran and the world summit on the information society. Tehran: City Press.

Najafi, S., \& Niblom, M. (2006). Iranian Youth and the Internet: six voices on internet use beyond the public and private spheres (Unpublished master's thesis). Stockholm school of Economics. Retrieved from www.arc.hhs.se.

Naqib al-Sadat, S. R. (2012). Public sphere in cyberspace. Social Science Quarterly, 57(1), 109-152.

Nozari, H. A. (2002). Read Habermas, an introduction to Jürgen Habermas's ideas and ideas. Tehran: Cheshme Publishing.

O’Brien, R. (2003). Civil Society: the Public Sphere and the Internet. Retrieved from www.web.net

Rabiei, A., Alikhani, Z., \& Gholami, F. (2012). Analysis of socio-political blogs with Habermas public domain approach. World Media Journal, 7(14), 90-123.

Rabiei, A., \& Ismaili, A. (2010). Study on news media reliability among citizens of Tehrani during social transformations before and after presidential elections 2009. Cultural Studies and Communication, 6(19), 11-28.

Rasmassen, T. (2013). Internet-based media. Europe and the political public sphere. Media Culture Society, 35(1), 97-104.

Seyed Alavi, S. M., \& Naqib al-Sadat, S. R. (2011). Public sphere in cyberspace Formed components of cyberspace from the viewpoint of experts in communication and political science at Iranian universities. Social Science Quarterly, 57, 159-102.

Tong, J. (2015). The formation of an agonistic public sphere: Emotions, the Internet and news media in China. China Information, 29(3), 1-19.

Yazd khasti, B., Adlipour, S., \& Sepehri, A. (2014). Content analysis of Facebook social network pages and groups with Habermas public sphere theory. Iranian Journal of Social Studies and Research, 1(1), 11-87.

Webster, F. (2002). Information society theories (I. Ghadimi, Tran.). Tehran: Qasedeh Sara Publications. 